\title{
CORRIGENDUM
}

\section{The skin microbiome}

Elizabeth A. Grice and Julia A. Segre

Nature Reviews Microbiology 9, 244-253 (2011)

It has been brought to our attention that in FIG. 1 of the original article the morphology and localization of the Demodex mites were not accurate. We have corrected the figure to show a cartoon that is more representative of the straight body and short limbs of these mites, and of their localization in the hair follicle. The correct figure is shown below. We thank I. Dekio for bringing this to our attention and apologize to readers for any confusion caused.

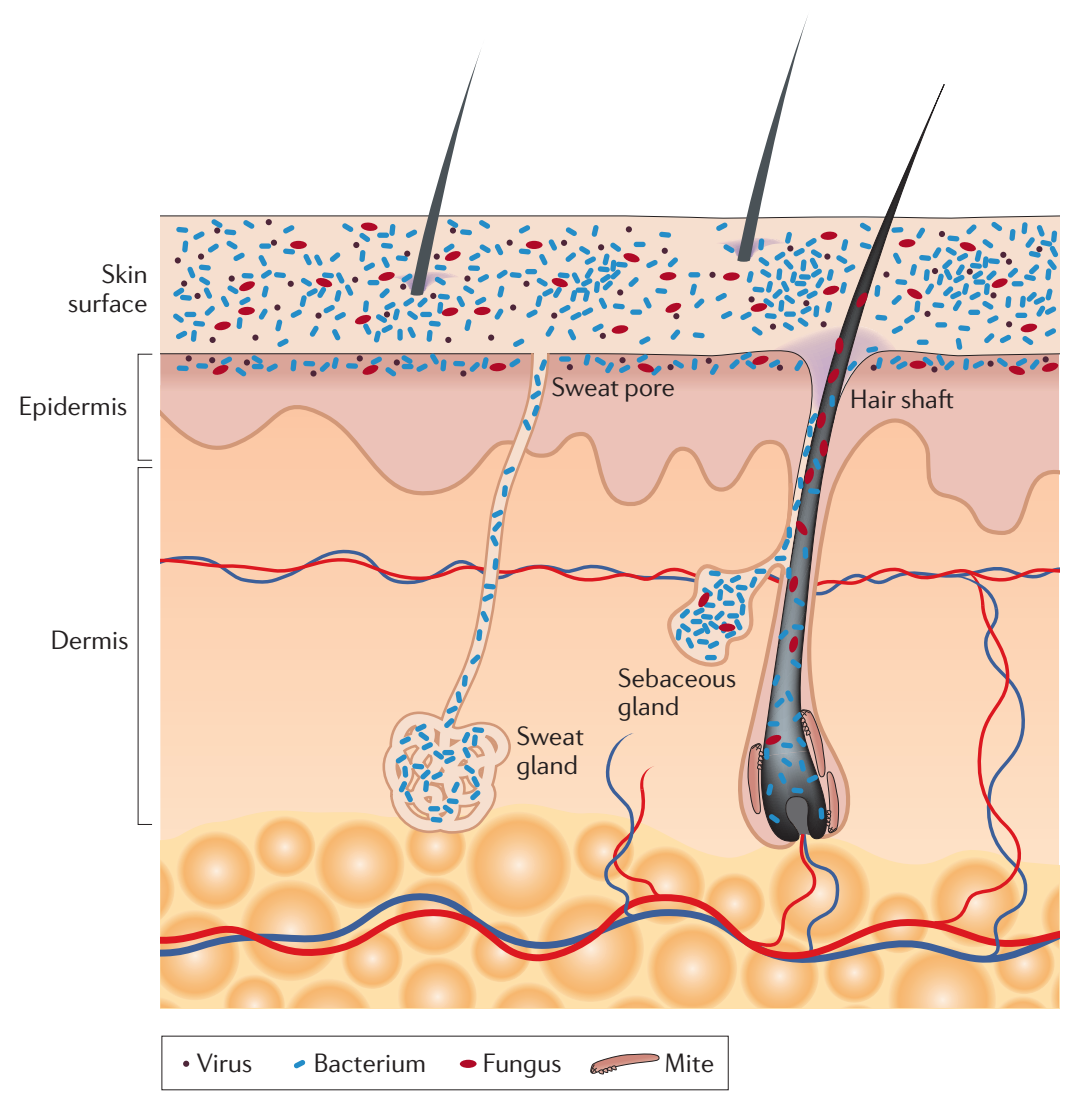

